\title{
Faktor-Faktor yang Berhubungan dengan Mitos-Mitos dalam Pemberian ASI Eksklusif di Wilayah Kerja Pukesmas Baiturrahman Banda Aceh
}

\author{
Faktors Related to Myths in Exclusive Brestfeeding in The Work Area of \\ Baiturrahman Health Center Banda Aceh \\ Nuzulul Rahmi*1, Annisah ${ }^{2}$ \\ ${ }^{1,2}$ Program Studi D-III Kebidanan, Fakultas Ilmu Kesehatan, Universitas Ubudiyah Indonesia, Banda Aceh, Indonesia \\ *Korespondensi Penulis: nuzulul_r@uui.ac.id
}

\begin{abstract}
Abstrak
Mitos-mitos turun temurun, anjuran, larangan, dari orang tua yang beredar di masyarakat membuat seorang ibu kurang percaya diri untuk memberikan ASI eksklusif kepada bayinya. Berdasaran observasi di wilayah kerja puskesmas Baiturrahman Banda Aceh dari bulan Januari sampai April 2016, jumlah kunjungan ibu menyusui berkisar 131 ,ditemukan 67,9\% yang tidak memberikan ASI eksklusif dan masih tidak mengetahui Fakta dan mitos dalam pemberian ASI. Penelitian ini bersifat analitik dengan pendekatan Cross Sectional. Populasi adalah ibu menyusui yang berkunjung ke wilayah Kerja puskesmas Baiturrahman yaitu 131 orang, pengambilan sampel diambil 57 orang, menggunakan rumus slovin dan selanjutnya dibagikan kuesioner kepada responden. Penelitian dilakukan tanggal 4-8 November 2016, Kemudian di uji statistik menggunakan Chi-square, Ho ditolak jika p value $>0,05$ dan Ha diterima jika $\mathrm{p}$ value $<0,05$. Hasil yang didapatkan ada hubungan pengetahuan ( $\mathrm{p}$-value $=$ $0,019)$, sikap ( $\mathrm{p}$ value $=0,017)$, lingkungan $(\mathrm{p}$ value $=0,038)$ dan pendidikan $(\mathrm{p}$ value $=$ 0,031) dengan mitos-mitos dalam pemberian ASI eksklusif di Puskesmas Baiturrahman tahun 2016. Saran kepada ibu agar selalu memberikan ASI Eksklusif kepada bayi hanya ASI yang memiliki kandungan paling lengkap menambah kekebalan tubuh, dan jangan mempercayai tentang mitos-mitos dalam pemberian ASI eksklusif.
\end{abstract}

Kata kunci : mitos-mitos, asi ekslusif, pemberian asi

\begin{abstract}
Myths from generation to generation, recommendations, prohibitions, from parents circulating in the community make a mother less confident to give exclusive breastfeeding to her baby. Based on observations in the work area of Baiturrahman Health Center Banda Aceh from January to April 2016, the number of visits by breastfeeding mothers ranged from 131, found 67.9\% who did not give exclusive breastfeeding and still did not know the facts and myths in breastfeeding. This research is analytical with Cross Sectional approach. The population was breastfeeding mothers who visited the Baiturrahman Community Health Center work area, 131 people, taking samples of 57 people, using the Slovin formula and then distributing questionnaires to the respondents. The study was conducted on 4-8 November 2016, then in the statistical test using Chi-square, Ho was rejected if $p$ value $>0.05$ and $\mathrm{Ha}$ was accepted if $p$ value $<0.05$. The results obtained there is a relationship of knowledge ( $p$ value $=0.019)$, attitude ( $p$ value $=0.017)$, environment $(p$ value $=0.038)$ and education $(p$
\end{abstract}


value $=0.031)$ with myths in exclusive breastfeeding at Baiturrahman Health Center in 2016 Suggestion for mothers to always give exclusive breastfeeding to babies is only breast milk which has the most complete content to increase immunity, and do not believe in myths in exclusive breastfeeding.

Keywords: myths, exclusive breastfeeding, breastfeeding

\section{PENDAHULUAN}

Mitos-mitos yang disampaikan secara turun temurun, anjuran, larangan, dari orang tua yang beredar di masyarakat membuat seorang ibu kurang percaya diri untuk memberikan ASI eksklusif kepada bayinya ketakutan yang tidak beralasan membuat seorang ibu berhenti menyusui dan beralih pada susu formula, dan mitos-mitos yang semakin berkembang bahwa menyusui dapat membuat tubuh seorang ibu menjadirusak, tubuh seorang ibu menjadi gemuk.Informasi-informasi yang tidak benar tersebut membuat seorang ibu semakin khawatir untuk memberikan ASI eksklusif.

Kegagalan dalam menyusui eksklusif disebabkan oleh banyak factor seperti yang dikemukakan dalam penelitiannya oleh Sartono dan Utaminingrum (2012). Salah satu faktor tersebut seperti pengetahuan dan kesadaran ibu akan pentingnya pemberian ASI secara eksklusif. Pengetahuan ibu yang didapatkan dari orang lain seperti orang tua dan kerabat merupakan informasi yang belum tentu kebenarannya atau disebut juga dengan mitos. Mitos mitos inilah yang banyak menyebabkan kesalahan dan kekeliruan dalam proses menyusui.

Berdasarkan studi pendahuluan yang penulis lakukan bahwa setelah peneliti mewawancarai beberapa dari ibu yang tidak memberikan ASI eksklusif di wilayah puskesmas Baiturahman Banda Aceh Tahun 2016,bahwa masih ada yang mempercayai mitos-mitos dalam pemberian ASI contohnya : ASI yang keluar pertama kali harus dibuang karena merupakan ASI lama (BASI), pemberian ASI dilarang bagi bayi yang diare, jika payudara kecil, maka produksi ASI kecil, menyusui dapat menyebabkan payudara menjadi kendur.

\section{METODE PENELITIAN}

Jenis penelitian ini bersifat survey dengan pendekatan cross sectional dalam hal ini peneliti ingin mengetahui faktor-faktor yang berhubungan dengan mitos-mitos dalam pemberian ASI Di Wilayah Kerja Puskesmas Baiturrahman Banda Aceh tahun 2016. Populasi dalam penelitian ini adalah seluruh ibu menyusui yang berkunjung ke wilayah Kerja puskesmas Baiturrahman sejak bulan januari 2015 sampai dengan April 2016 yang berjumlah 
131 orang. Berdasarkan perhitungan sampel diatas maka dapat di simpulkan Jumlah sampel dalam setiap Desa di Wilayah kerja Puskesmas Baiturrahman Kota Banda Aceh adalah 57 orang.

Alat pengumpulan data yang digunakan dalam penelitian ini adalah kuisioner tentang faktor- faktor yang berhubungan dengan mitos-mitos dalam pemberian ASI eksklusif diwilayah kerja puskesmas baiturrahman banda aceh yang terdiri dari 27 pertanyaan. Analisa yang digunakan adalah hasil tabulasi silang. Untuk menguji hipotesa dilakukan analisa statistic dengan uji Chi - Square Tes (x) pada tingkat kemaknaan 95\% (p. Value <0,05). Sehingga dapat diketahui perbedaan tidaknya yang bermakna secara statistic, dengan menggunakan program khusus SPSS for windows. Melalui perhitungan Chis - Square selanjutnya ditarik suatu kesimpulan, bila nilai $\mathrm{P}$ lebih kecil dari nilai $\alpha(0,05)$, maka Ho ditolak dan Ha diterima, yang menunjukkan ada hubungan bermakna antara variabel terikat dengan variabel bebas.

\section{HASIL DAN PEMBAHASAN}

Tabel 1. Hubungan Tingkat Pengetahuan Ibu dengan Mitos-Mitos dalam Pemberian ASI Eksklusif di Puskesmas Baiturrahman Tahun 2016

\begin{tabular}{|c|c|c|c|c|c|c|c|c|}
\hline \multirow{3}{*}{ No } & \multirow{3}{*}{ Pengetahuan } & \multicolumn{4}{|c|}{$\begin{array}{c}\text { Mitos-Mitos Dalam Pemberian } \\
\text { ASI Eksklusif } \\
\end{array}$} & \multirow{2}{*}{\multicolumn{2}{|c|}{ Total }} & \multirow[t]{3}{*}{ P-value } \\
\hline & & \multicolumn{2}{|c|}{ Fakta } & \multicolumn{2}{|c|}{ Mitos } & & & \\
\hline & & $\mathbf{f}$ & $\%$ & f & $\%$ & f & $\%$ & \\
\hline 1 & Tinggi & 14 & 73,7 & 5 & 26,3 & 19 & 100 & \\
\hline 2 & Sedang & 5 & 33,3 & 10 & 66,7 & 15 & 100 & 0.019 \\
\hline \multirow[t]{2}{*}{3} & Rendah & 8 & 34,8 & 15 & 65,2 & 23 & 100 & \\
\hline & Jumlah & 27 & & 30 & & 57 & 100 & \\
\hline
\end{tabular}

Berdasarkan tabel dapat dilihat bahwa dari 14 responden yang bepengetahuantinggi dan percaya dengan mitos dalam pemberian Asi eksklusif sebesar 73,7\%. dari5 responden yang bepengetahuan sedang dan percaya dengan mitos dalam pemberian Asi eksklusif sebesar $33,3 \%$. Dan dari 8 responden yang bepengetahuan rendah dan percaya dengan mitos dalam pemberian Asi eksklusif sebesar 34,8\%.

Hasil analisis statistik menggunakan uji chi-square didapatkan p-value $=0,019$. Sehingga dapat disimpulkan bahwa $\mathrm{p}<0,05$ yang artinya Ha diterima atau terdapat hubungan 
tingkat pengetahuan ibu dengan mitos-mitos dalam pemberian Asi eksklusif di Puskesmas Baiturrahman tahun 2016.

Hasil penelitian ini sama dengan penelitian yang dilakukan oleh Trilestari (2012) dengan hasil berpengatahuan baik sebanyak 74,6 \%, cukup sebanyak 19,0 \% dan kurang sebanyak 6,3\%. Untuk mitos kategori baik sebanyak 46,0 \%, kurang sebanyak 54,0 \%. Pada praktek menyusui kategori baik sebanyak 87,3\%, kurang sebanyak 12,7\%. Sedangkan pemberian ASI Eksklusif kategori nol sebanyak 79,4\% yang berarti tidak memberikan ASI Eksklusif dan nilai satu sebanyak 20,6 \% yang berarti memberikan ASI Eksklusif. Menurut peneliti, pengetahuan ibu akan sangat berpengaruh terhadap kepercayaan yang berhubungan dengan mitos-mitos dalam pemberian ASI eksklusif pada bayi, sehingga semakin tinggi pengetahuan ibumaka akan semakin positif tentang hal-hal yang kebenarannya nyata serta akan semakin negatif terhadap hal-hal seperti mitos-mitos dalampemberian ASI Eksklusif yang kebenarannya belum tentu benar adanya. Oleh karena itu,disini sangat dibutuhkan peran tenaga kesehatan dalam memberikan informasi seperti penyuluhan kepada ibu tentang ASI eksklusif.

Tabel 2. Hubungan Sikap Ibu dengan Mitos-Mitos dalam Pemberian ASI Eksklusif di Puskesmas Baiturrahman Tahun 2016

\begin{tabular}{|c|c|c|c|c|c|c|c|c|}
\hline \multirow{3}{*}{ No } & \multirow{3}{*}{ Sikap } & \multicolumn{4}{|c|}{$\begin{array}{c}\text { Mitos-Mitos Dalam Pemberian } \\
\text { ASI Eksklusif }\end{array}$} & \multirow{2}{*}{\multicolumn{2}{|c|}{ Total }} & \multirow[t]{3}{*}{ P-value } \\
\hline & & \multicolumn{2}{|c|}{ Fakta } & \multicolumn{2}{|c|}{ Mitos } & & & \\
\hline & & $\mathbf{f}$ & $\%$ & $\mathbf{f}$ & $\%$ & $\mathbf{f}$ & $\%$ & \\
\hline 1 & Positif & 21 & 61,8 & 13 & 38,2 & 34 & 100 & \\
\hline 2 & Negatif & 6 & 26,1 & 17 & 73,9 & 23 & 100 & 0,017 \\
\hline & Jumlah & 27 & & 30 & & 57 & 100 & \\
\hline
\end{tabular}

Berdasarkan tabel dapat dilihat bahwa dari 21responden dengan sikap yang positif danpercaya dengan mitos sebesar $61,8 \%$, sedangkan dari 6 responden dengan sikap yang negativedan percaya dengan mitos sebesar $26,1 \%$. Hasil analisis statistik menggunakan uji chi-square didapatkan $\mathrm{p}$ value $=0,017$. Sehingga dapat disimpulkan bahwa $\mathrm{p}<0,05$ yang artinya Ha diterima atau terdapat hubungan sikap ibu dengan mitos-mitos dalam pemberian Asi eksklusif di Puskesmas Baiturrahman tahun 2016.

Hasil penelitian ini sama dengan penelitian yang dilakukan oleh Berdasarkan hasil penelitian yang dilakukan oleh Azura (2011) yang berjudul hubungan sikap, pendidikan, dan pengetahuan dengan kepercayaan ibu menyusui terhadap mitos-mitos di wilayah kerja 
Puskesmas Antapani Bandung Jawa Barat menunjukkah bahwa ada hubungan sikap dengan kepercayaan ibu hamil terhadap mitos-mitos pemberian ASI ekslusif dengan p value 0,017.

Menurut peneliti, sikap merupakan kesiapan seseorang dalam bertindak sehingga akan sangat berpengaruh terhadap tindakan yang dilakukan oleh seseorang. Semakin positif sikap ibu maka akan semakin positif pula pandangan ibutentang mitos-mitos dalam pemberian ASI Eksklusif.maka upaya yang harus dilakukan adalah dengan memberikan konseling tentang pemberian ASI eksklusif.

Tabel 3. Hubungan Lingkungan Ibu dengan Mitos-Mitos dalam Pemberian ASI Eksklusif di Puskesmas Baiturrahman Tahun 2016

\begin{tabular}{|c|c|c|c|c|c|c|c|c|}
\hline \multirow{3}{*}{ No } & \multirow{3}{*}{ Lingkungan } & \multicolumn{4}{|c|}{$\begin{array}{c}\text { Mitos-Mitos Dalam } \\
\text { Pemberian ASI Eksklusif }\end{array}$} & \multirow{2}{*}{\multicolumn{2}{|c|}{ Total }} & \multirow[t]{3}{*}{ P-value } \\
\hline & & \multicolumn{2}{|c|}{ Fakta } & \multicolumn{2}{|c|}{ Mitos } & & & \\
\hline & & $\mathbf{F}$ & $\%$ & $\mathbf{F}$ & $\%$ & $\mathbf{F}$ & $\%$ & \\
\hline 1 & Baik & 20 & 60,6 & 13 & 39,4 & 33 & 100 & \\
\hline 2 & Kurang Baik & 7 & 29,2 & 17 & 70,8 & 24 & 100 & 0,038 \\
\hline & Jumlah & 27 & & 30 & & 57 & 100 & \\
\hline
\end{tabular}

Berdasarkan tabel dapat dilihat bahwa dari 20responden dengan lingkungan baik dan percaya dengan mitos sebesar $60,6 \%$, Sedangkan dari 7 responden dengan lingkungan kurang baik dan percaya dengan mitos sebesar 29,2\%. Hasil analisis statistik menggunakan uji chisquare didapatkan $\mathrm{p}$ value $=0,038$. Sehingga dapat disimpulkan bahwa $\mathrm{p}<0,05$ yang artinya Ha diterima atau terdapat hubungan lingkungan ibu dengan mitos-mitos dalam pemberian Asi eksklusif di Puskesmas Baiturrahman tahun 2016.

Hasil penelitian ini sama dengan penelitian yang dilakukan oleh Listiana (2012) yang berjudul faktor-faktor yang mempengaruhi kepercayaan ibu nifas terhadap mitos-mitos di wilayah kerja Puskesmas Manggeng Aceh Barat Daya menunjukkah bahwa ada pengaruh lingkungan dengan kepercayaan ibu nifas terhadap mitos-mitos pemberian ASI Eksklusif dengan ( $p$ value 0,001$)$.

Menurut asumsi peneliti, lingkungan adalah segala sesuatu yang ada disekitar ibu menyusui, Semakin baik lingkungan lingkungan masyarakat disekitar ibu, maka akan semakin positif pengaruh terhadap mitos-mitos dalam pemberian ASI eksklusif, begitu juga sebaliknya dimana semakin rendah lingkungan disekitar ibu, maka akan semakin negatif pengaruh terhadap mitos-mitos dalam pemberian ASI eksklusif, upaya yang harus dilakukan dengan memberikan sosialisasi tentang pemberian ASI eksklusif pada bayi. 
Tabel 4. Hubungan Pendidikan Ibu terhadap Mitos-Mitos dalam Pemberian ASI Eksklusif di Puskesmas Baiturrahman Tahun 2016

\begin{tabular}{|c|c|c|c|c|c|c|c|c|}
\hline \multirow{3}{*}{ No } & \multirow{3}{*}{ Pendidikan } & \multicolumn{4}{|c|}{$\begin{array}{c}\text { Mitos-Mitos Dalam } \\
\text { Pemberian ASI Eksklusif }\end{array}$} & \multirow{2}{*}{\multicolumn{2}{|c|}{ Total }} & \multirow[t]{3}{*}{ P-value } \\
\hline & & \multicolumn{2}{|c|}{ Fakta } & \multicolumn{2}{|c|}{ Mitos } & & & \\
\hline & & $\mathbf{f}$ & $\%$ & $\mathbf{f}$ & $\%$ & $\mathbf{f}$ & $\%$ & \\
\hline 1 & Tinggi & 13 & 72,2 & 5 & 27,8 & 18 & 100 & \\
\hline 2 & Menengah & 11 & 39,3 & 17 & 60,7 & 28 & 100 & $\mathbf{0 , 0 3 1}$ \\
\hline \multirow[t]{2}{*}{3} & Dasar & 3 & 27,3 & 8 & 72,7 & 11 & 100 & \\
\hline & Jumlah & 27 & & 30 & & 57 & 100 & \\
\hline
\end{tabular}

Berdasarkan tabel dapat dilihat bahwa dari 13 responden yang bepengetahuan tinggi dan percaya dengan mitos dalam pemberian Asi eksklusif sebesar 72,2\%. dari 11 responden yang bependidikan menengah dan percaya dengan mitos dalam pemberian Asi eksklusif sebesar 39,3\%. Dan dari 3 responden yang berpendidikan dasar dan percaya dengan mitos dalam pemberian Asi eksklusif sebesar 27,3\%. Hasil analisis statistik menggunakan uji chisquare didapatkan $\mathrm{p}$ value $=0,031$. Sehingga dapat disimpulkan bahwa $\mathrm{p}<0,05$ yang artinya Ha diterima atau terdapat hubungan pendidikan ibu dengan mitos-mitos dalam pemberian Asi eksklusif di Puskesmas Baiturrahman tahun 2016.

Hasil penelitian ini sama dengan penelitian yang dilakukan oleh Jannah (2010) yang berjudul hubungan sikap, pendidikan, dan pengetahuan dengan kepercayaan ibu menyusui terhadap mitos-mitos dalam pemberian ASI eksklusif di wilayah kerja Puskesmas Trumon Aceh Selatan menunjukkan bahwa ada hubungan pendidikan dengan kepercayaan ibu menyusuiterhadap mitos-mitos dalampemberian ASI Eksklusif dengan $p$ value 0,008.

Menurut peneliti pendidikan adalah hal yang sangat dibutuhkan oleh setiap individu. Semakin tinggi pendidikan seseorang, maka akan semakin terbuka pemikirannya sehingga akan dapat membedakan hal yang bernar adanya dan yang diragukan kebenaranya seperti halnya mitos-mitos selama masa menyusui salah satunya apabila semakin tinggi tingkat pendidikan seorang ibu, maka semakin rendah kepercayaan terhadap mitos selama memberikan ASI Ekslusif.jadi upaya yang harus dilakukan dengan memberikan pelatihan peningkatan kapasitas ibu tentang pemberian ASI eksklusif pada bayi. 


\section{KESIMPULAN}

Ada hubungan pengetahuan $(\mathrm{p}$-value $=0,019)$, sikap $(\mathrm{p}$ value $=0,017)$, lingkungan $(\mathrm{p}$ value $=0,038)$ dan pendidikan $(\mathrm{p}$ value $=0,031)$ dengan mitos-mitos dalam pemberian ASI eksklusif di Puskesmas Baiturrahman tahun 2016.

\section{SARAN}

Saran kepada ibu agar selalu memberikan ASI Eksklusif kepada bayi hanya ASI yang memiliki kandungan paling lengkap menambah kekebalan tubuh, dan jangan mempercayai tentang mitos-mitos dalam pemberian ASI eksklusif.

\section{DAFTAR PUSTAKA}

Agus Sartono dan Hanik Utaminingrum. (2012). Hubungan Pengetahuan Ibu, Pendidikan Ibu dan Dukungan Suami dengan Praktek Pemberian Asi Eksklusif di Kelurahan Muktiharjo Kidul Kecamatan Telogosari Kota Semarang. Volume 01 No.01 November 2012. ISSN : 2302-7908

Purwanti. (2012). Hubungan sikap, pendidikan, dan pengetahuan dengan kepercayaan ibu menyusui terhadap mitos-mitos di wilayah kerja Puskesmas Antapani Bandung Jawa Barat. Skripsi

Lestari. (2014). Faktor-faktor yang berhubungan dengan Gejala ISPA pada Balita di Desa Citeureup. Skripsi.

Listiana. (2012). Faktor-faktor yang mempengaruhi kepercayaan ibu nifas terhadap mitosmitos di wilayah kerja Puskesmas Manggeng Aceh Barat Daya. Skripsi

Jannah. (2010). Hubungan sikap, pendidikan, dan pengetahuan dengan kepercayaan ibu menyusui terhadap mitos-mitos dalam pemberian ASI eksklusif di wilayah kerja Puskesmas Trumon Aceh Selatan. Tesis

Nirwana. (2014). ASI dan Susu Formula, Yogyakarta.Nuha Medika.

Utami. (2011). Bayi sehat berkat ASI eksklusif,makanan pendamping tepat dan imunisasi lengkap.Jakarta :Penerbit PT .Elex Media Komputindo.

Widiyanto. (2012). Hubungan Pendidikan Dan Pengetahuan Ibu Tentang ASI Dengan Sikap Terhadap Pemberian ASI Eksklusif

Junarti. (2011). Faktor-faktor yang berhubungan dengan ASI eksklusif pada bayi di kelurahan maricaya baru wilayah kerja puskesmas maradekaya kota Makassar. Dikutip tanggal 12 Januari 2016. 